\title{
OROGRAPHICALLY FORCED STRATOSPHERIC WAVES OVER NORTHERN SCANDINAVIA
}

\author{
Hans Volkert ${ }^{1}$ and Didier Intes ${ }^{1,2}$
}

\begin{abstract}
Simulations were carried out using the two-dimensional version of a non-hydrostatic numerical model in order to calculate the mesoscale response to flow across the Scandinavian mountain range. The initial conditions were deduced from an upstream sounding of 27 January 1992 during the EASOE campaign. Over and to the east of the mountain crest regions of mesoscale extent developed which experienced cooling up to $7 \mathrm{~K}$. Air parcel trajectories passed these areas in approximately $10 \mathrm{~min}$.
\end{abstract}

\section{Introduction}

The European Arctic Stratospheric Ozone Experiment (EASOE) took place during the winter months 1991/92 in order to monitor concentrations of ozone and other trace gas species within the Arctic stratosphere and, in particular, during the occurence of polar stratospheric clouds (PSC). For the formation of PSC the air temperature has to fall below a certain threshold value deperiding on the ambient pressure and the trace gas concentration $\left(-85^{\circ} \mathrm{C}\right.$ is a typical value for heights of $20 \mathrm{~km}$ or the $50 \mathrm{hPa}$ pressure level; see e.g. Amold et al., 1989).

During EASOE hemispheric trajectories were calculated for specific isentropic levels $(350,380,400$, $475,550,700 \mathrm{~K}$ ) with the operational model of ECMWF. Temperature, humidity and pressure information along such trajectories were transmitted to the EASOE operation centre in Kinura where a trajectory box model was applied to calculate estimates for the concentrations of chemical species (Peter, personal comunication). Due to their limited vertical and horizonital resolution the predicted temperatures were often significantly higher than those measured, and they were above the threshold for PSC formation (c.f. Peter et al., 1992, for a pre-EASOE case study). Therefore mechanisms are sought which produce cooling relative to the global forecasts.

Orographically forced waves are known to provide such a mechanism. Observations and simulations using a linear model are available for Antarctic cases (Bacmeister et al., 1990; Cariolle et al., 1989). The purpose of this study is to apply a fully non-linear model to simulate the stratospheric wave field in a two-dimensional section across the Scandinavian mountains for one particular EASOE case. First, we

\footnotetext{
'DLR, Institut für Physik der Atmosphäre, Oberpfaffenhofen, FRG

${ }^{2}$ on leave from EDF, Laboratoire National d' Hydraulique, Chatou, F
}

Copyright 1992 by the American Geophysical Union.

Paper number 92GL01160

0094-8534/92/92GL-01160\$03.00 outline model details specific to this study; secondly, the geographical situation of the regular sounding stations and the model section is sketched; the presentation of results for 27 January 1992 makes up the central part of the paper, while the discussion concludes it.

\section{Modelling strategy}

It was decided to use the two-dimensional version of the mesoscale model, which was developed by Schumann et al. (1987), as a first step towards the simulation of orographically forced waves in the stratosphere. This allows good resolution $(\Delta x=3.1 \mathrm{~km}$; $\Delta \mathrm{z}=0.5 \mathrm{~km}$; see tick marks in Figure 5) over a domain of $660 \mathrm{~km}$ by $36 \mathrm{~km}$ at reasonable computational expense (an $5 \mathrm{~h}$ integration takes about $850 \mathrm{~s}$ computing time on a single Cray processor). Furthermore, the initial conditions can be specified by one typical upstream profile for zonal wind and temperature which is extended to the entire domain under observation of the discrete equation of continuity on the terrain following numerical grid.

A general model description is given in Schumann et al. (1987) together with the treatment of the linear and non-linear Long problem as evaluation example for gravity waves in two-dimensional flow over orography. Three modifications were introduced for this study. First, the simple Boussinesq approximation with constant background density was replaced by the height dependent basic state as in Clark and Farley (1984); second, at the inflow boundary a radiative

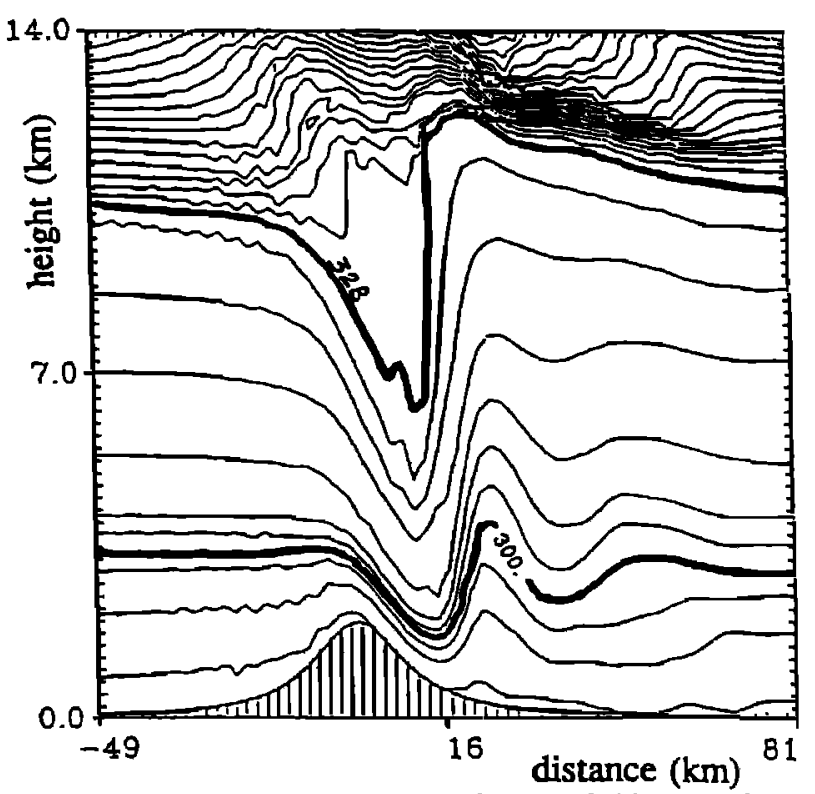

Fig. 1. Control nun for Boulder Storm of $11 \mathrm{Jan} .1972$. Isentropes $2 \mathrm{~h}$ after initialization; increment: $4 \mathrm{~K}$. 


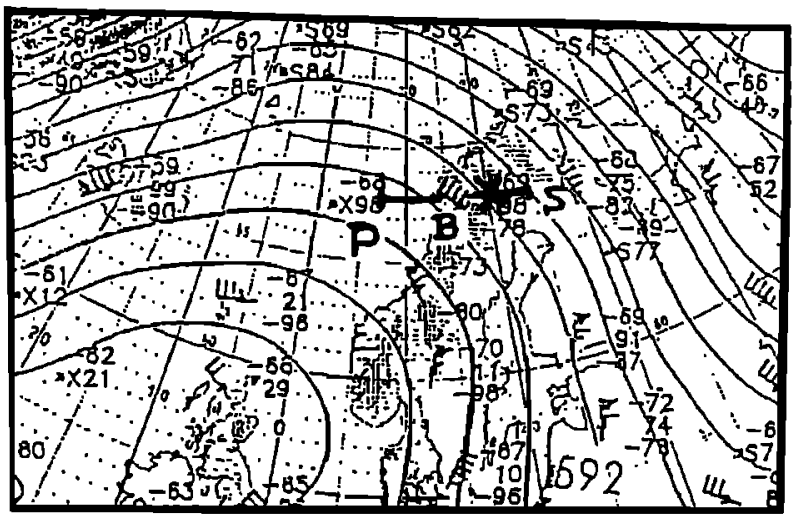

Fig. 2. Synoptic chart of the $100 \mathrm{hPa}$ level over northern Europe for 27 Jan. 1992, 12 UTC; full lines: geopotential height with $80 \mathrm{gpm}$ increment (from: Europäischer Wetterbericht, DWD, Offenbach). Single letters designate: weathership Polarfront (P), Bodø (B), Sodankyla (S). The curved heavy line near $68^{\circ} \mathrm{N}$ indicates the position of the model cross-section and $x$ the approximate position of Kiruna.

condition is applied as proposed by Klemp and Lilly (1978), which allows upstream travelling disturbances to leave the domain while keeping the inflow profiles close to the initial ones; and third, a layer of damping linearly increasing with height was introduced for the region above $27.5 \mathrm{~km}$; at the model top in $36 \mathrm{~km}$ the radiative condition due to Bougeault, Klemp and Durran is used as outlined in Schumann et al. (1987).

As model evaluations we carried out runs for the Long problem and the frequently documented Boulder Storm of $11 \mathrm{Jan}$. 1972. The Long problem proved to be insensitive to the modifications mentioned except that the isentropes over the mountain became pronounced at higher levels. A sample result of the Boulder Storm calculation is given in Figure 1. The overall structure of the isentropes and particularly the region of largely reduced static stability below the tropopause is in very good agreement with the results of Xue and Thorpe (1991; c.f. their Figure 12b). As width and steepness of the mountain and the jet strength are less pronounced for Scandinavian cases,

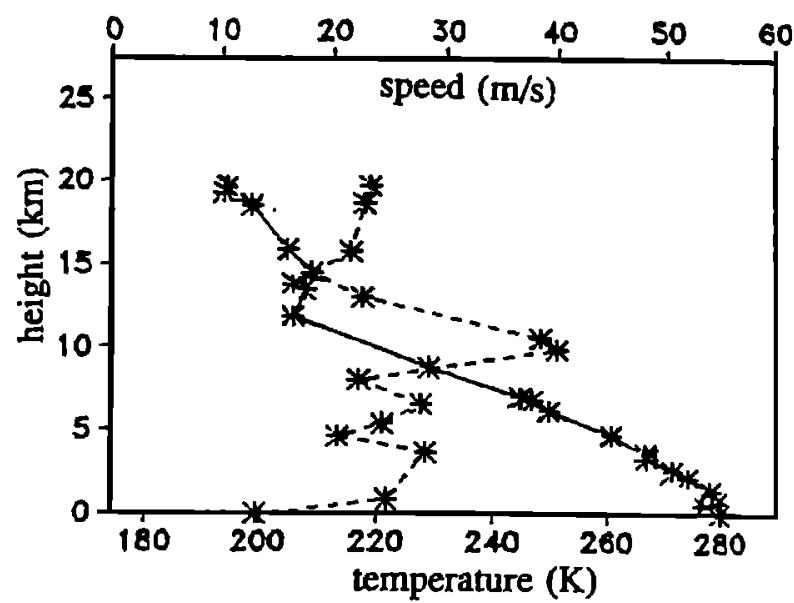

Fig. 3. Significant levels (*) of sounding from weathership Polarfront for 27 Jan. 1992, 00 UTC; temperature (full line) and zonal velocity component (dashed line). we conclude that the model is an apt tool for this study.

\section{Geographic situation}

The position of the regular soundings stations Polarfront (weather ship), Bodø and Sodankyla is given in Figure 2. They make up a west to east cross-section passing through Kiruna from where a lot of special balloon missions were carried out during EASOE.

Although the synoptic scale flow in the $100 \mathrm{hPa}$ level is from a northwesterly direction on 27 January 1992 (Figure 2), we use the indicated west-east section for our calculations and the Polarfront sounding for the deduction of the initial profile. This appears to be reasonable as no off-shore sounding is available further to the north and as the flow is from the west within the troposphere. The particular date was chosen, as quick look results from balloon flights suggest stratospheric waves for that day.

The orographic heights were taken from a section at $68^{\circ} \mathrm{N}$ through a database with $5^{\prime}$ resolution (available from the US Geographical Survey, Boulder, $\mathrm{CO}$ ). After application of a five point smoother we obtained a mountain profile with a crest height of $1550 \mathrm{~m}$ and a width of about $120 \mathrm{~km}$ (see Figure 5).

\section{Results for 27 January 1992}

The significant level data of temperature and the zonal velocity component of the Polarfront sounding are given in Figure 3. The summit level was at 53.7 $\mathrm{hPa}$ (i.e. $19.7 \mathrm{~km}$ ) with temperature as low as $-79^{\circ} \mathrm{C}$. A jet of $40 \mathrm{~m} / \mathrm{s}$ from $275^{\circ}$ was situated just below the tropopause. The significant level data are transformed into a system with height as vertical coordinate via the hydrostatic relation. The smoothed initial profiles for the calculation are displayed in Figure 4. The observed speed reduction within the boundary layer is not taken into account as the model uses a free slip boundary condition at the ground. Above $20 \mathrm{~km}$ temperature and speed are kept constant.

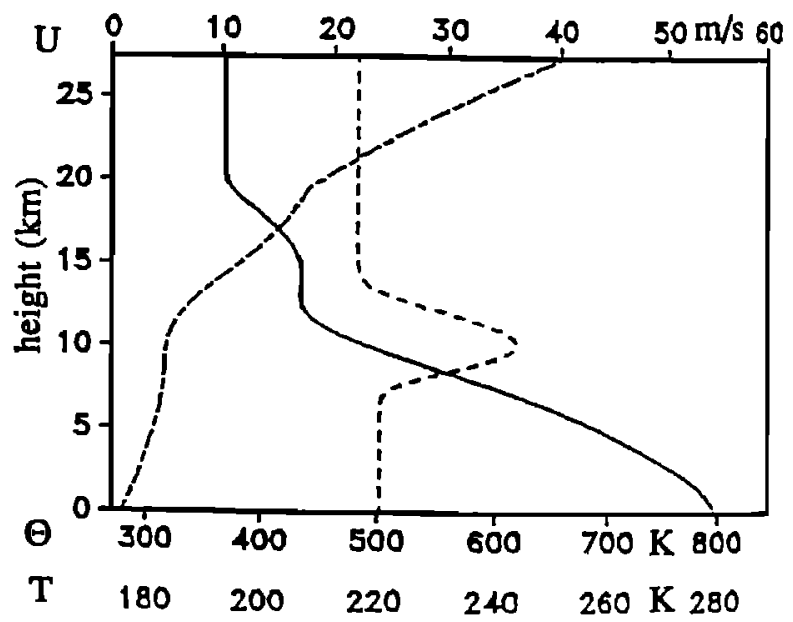

Fig. 4. Inflow profiles approximated from observations (c.f. Fig. 3); temperature (T; full line), potential temperature $(\theta$; long dashes), and zonal velocity (U; short dashes). 

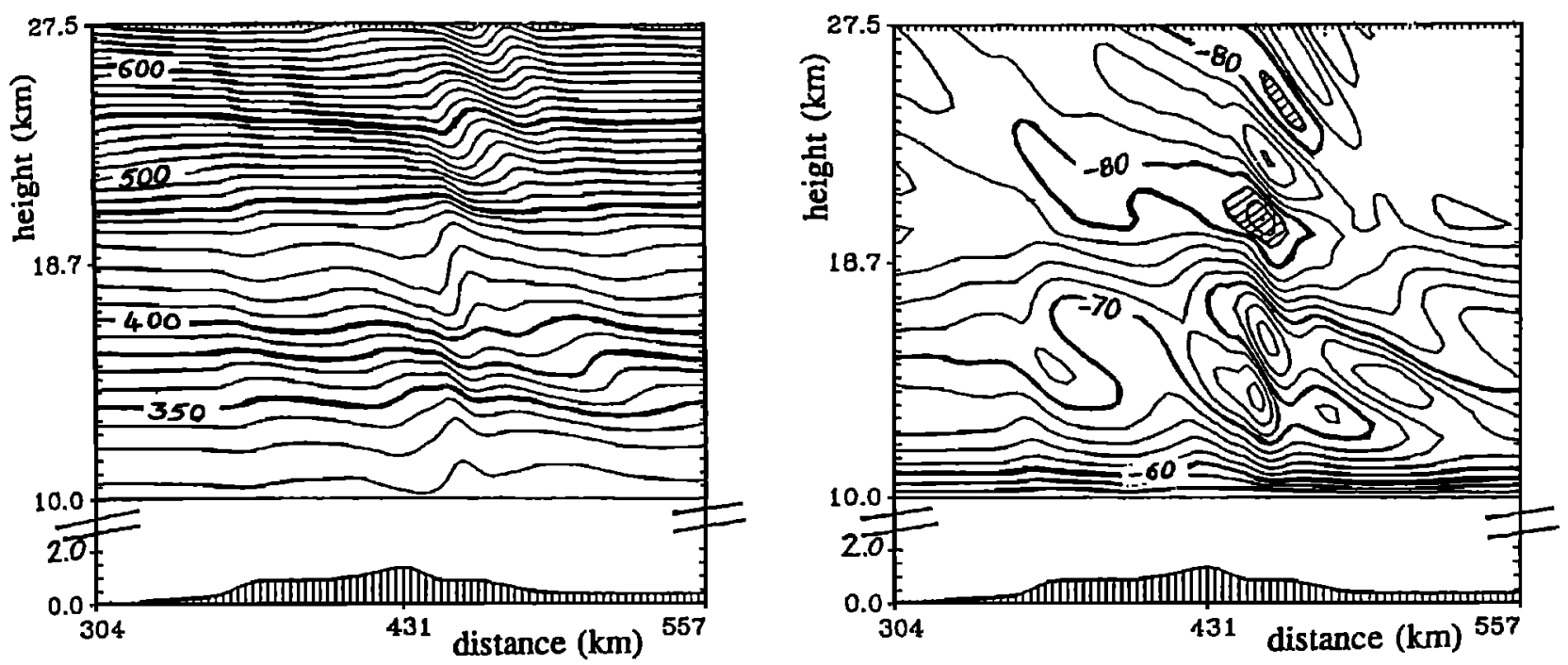

Fig. 5. Orographically disturbed fields of potential temperature (left; increment: $10 \mathrm{~K}$; thick lines are "standard EASOE values" $350,380,400,470$ [for 475 ], and $550 \mathrm{~K}$ ) and temperature (right; increment: $2 \mathrm{~K}$; regions below $-82^{\circ} \mathrm{C}$ hatched); displayed is the centre of the computational domain $4 \mathrm{~b}$ after initialization.

The orographically induced response to the initial profile is exemplified in Figure 5 for the centre of the computational domain and four hours after initialization. Just east of the mountain crest a significant wave is apparent with a nearly perpendicular isentrope (430 $\mathrm{K})$ between the 18 and $19 \mathrm{~km}$ height levels. The corresponding temperature distribution is obtained by taking into account the disturbances of potential temperature and pressure and the background basic state. Patches of reduced temperature (up to $7 \mathrm{~K}$ lower than in the initial profile) are present in regions in which isentropes descend eastwards.

Trajectories were calculated during the integration for air parcels which started west of the mountain range (at position $x=300 \mathrm{~km}$ ) and $2 \mathrm{~h}$ after initialization (Figure 6). The lower "standard EASOE isentropes" (350, 380, and $400 \mathrm{~K})$ experienced distinct height variations of approximately $1000 \mathrm{~m}$. The movement is fastest on the $350 \mathrm{~K}$ isentrope which is

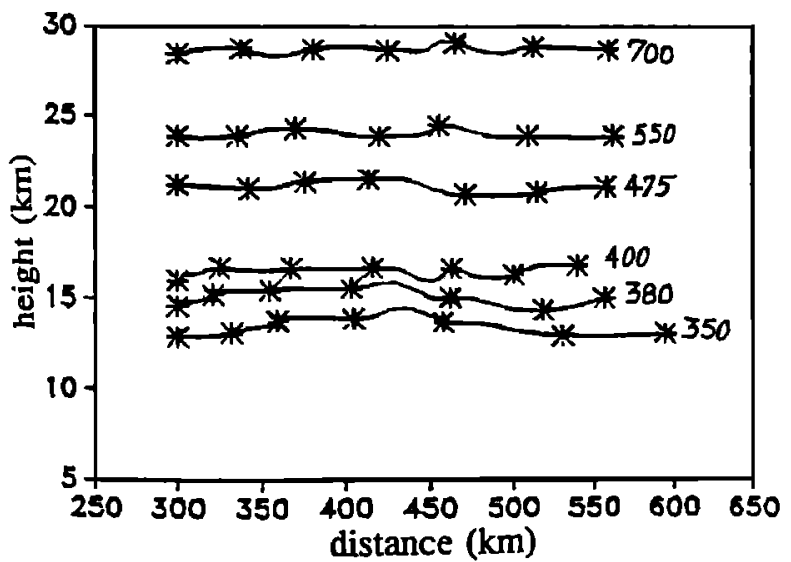

Fig. 6. Trajectories on "standard EASOE isentropes"; start $2 \mathrm{~h}$ hours after initialization at position $\mathrm{x}=300 \mathrm{~km} ; 30$ minute intervals indicated by $*$; mountain crest at position $x=430 \mathrm{~km}$ (c.f. Fig. 5). situated within the upper part of the jet region (see Figure 4). The trajectory calculation was performed for isentropes from 300 to $700 \mathrm{~K}$ spaced by $5 \mathrm{~K}$ and the resulting temperatures were stored every $5 \mathrm{~min}$. Figure 7 contains these data and reveals, e.g., that air on the $450 \mathrm{~K}$ isentrope passed the region with $\mathrm{T}<$ $-84^{\circ} \mathrm{C}$ within $10 \mathrm{~min}$.

Vertical temperature profiles just east of the mountain crest are displayed in Figure 8 . Above $13 \mathrm{~km}$ significant fluctuations with height $(\Delta \mathrm{T}>20 \mathrm{~K}$ over $5 \mathrm{~km}$ ) are present, which should be compared with measurements from balloons, which were released in Kiruna (see Schlager et al., 1990, for a pre-EASOE case).

\section{Discussion}

The two-dimensional model calculation, which was presented here, showed that orographically forced waves can extend into the stratosphere where they induce cooling in excess of $5 \mathrm{~K}$ relative to the inflow profile and significant temperature variations with

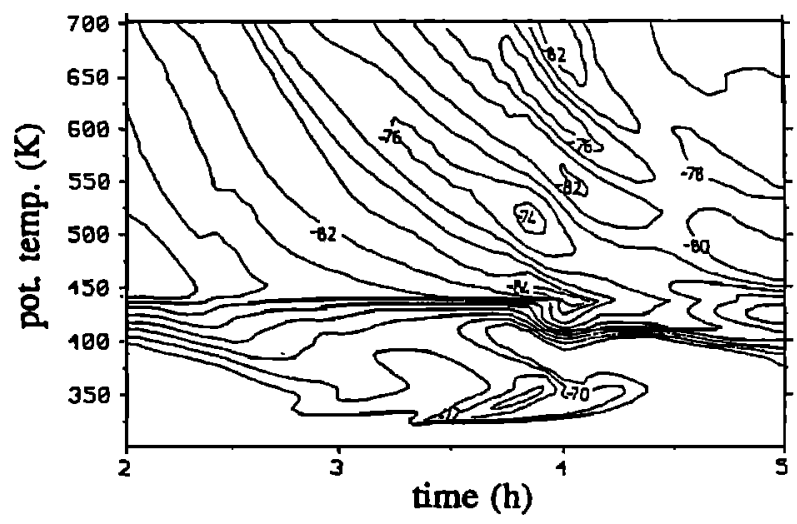

Fig. 7. Temperature (increment: $2 \mathrm{~K}$ ) along trajectories as function of model time and potential temperature. 


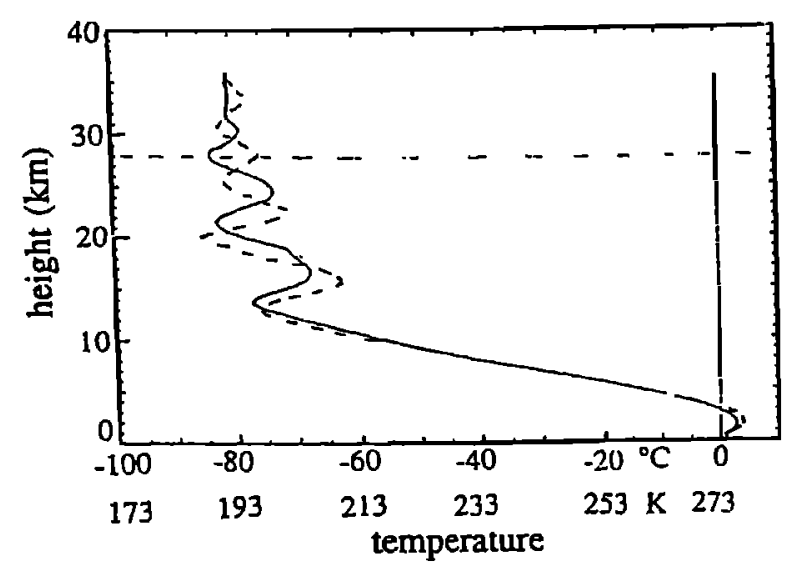

Fig. 8. Vertical temperature profile at position $x=450 \mathrm{~km}$ $4 \mathrm{~h}$ (dashed line) and $5 \mathrm{~h}$ (full line) after initialization.

height. Atmospheric microphysicists and chemists may judge whether the corresponding cooling periods, which are definitely shorter than one hour, are relevant to PSC formation and ozone destruction.

Similar results have been obtained for the case of 5 February 1990 when lee wave type PSC were observed from Kiruna. Numerical experimentation revealed that a pronounced jet at the tropopause level is necessary for the excitation of such stratospheric waves.

Unfortunately, the observed data did not extend to heights above $20 \mathrm{~km}$. During conditions of strong westerly flow one should ideally aim at three hourly soundings at weathership Polarfront and the stations Bodø, Kiruna, and Sodankyla (c.f. Figure 2) in order to validate the results of calculations as they were presented here.

A strong limitation of our approach is the restriction to two spatial dimensions. A three-dimensional mesoscale model within an operational weather service environment would certainly be a superior tool. Preliminary experiments and comparisons with observations have been carried out by Shutts (1992) for tropospheric heights. But these models do not have many stratospheric levels (c.f. Ballard et al., 1991, Figure 2). Our experimental model could be run in its threedimensional mode, if an analysis scheme were available to specify the boundary data.

In summary, we note that mesoscale dynamical processes, as e.g. Stratospheric mountain waves, may well have a significant impact on the atmospheric chemistry within the stratosphere. This should be taken into account during the data analyses of EASOE and the design of similar campaigns in the future.
Acknowledgements. This study is partly supported by the Commission of the European Communities under contract No. STEP-CT91-0140 (MNLA). The transfer of the sounding data was speedily undertaken by the Meteorologisches Institut der Freien Universität Berlin.

\section{References}

Anold, F., H. Schlager, J. Hoffmann, P. Metzinger and S. Spreng: Evidence for stratospheric nitric acid condensation from balloon and rocket measurements in the Arctic. Nature 342, 493-497, 1989.

Bacmeister, J.T., M.R. Schoeberl, L.S. Lait, P.A. Newman, B. Gray: ER-2 mountain wave encounter over Antartica: evidence for blocking. Geoplyys. Res. Lett., 17, 81-84, 1990.

Ballard, S.P., B.W. Golding, R.N.B. Smith: Mesocale model experimental forecasts of the Haar of northeast Scotland. Mon. Wea. Rev. 119, 2107-2123, 1991.

Cariolle, D., S. Muller, F. Cayla and M.P. McCormick: Mountain waves, polar stratospheric clouds, and the ozone depletion over Antarctica. J. Geophys. Res. 94, No. D9, 11233-11240, 1989.

Clark, T.L. and R.D. Farley: Severe downslope windstom calculations in two and three spatial dimension using anelastic interactive gridnesting: a possible mechanism for gustiness. J. Atmos. Sci. 41, 329-350, 1984.

Klemp, J.B. and D.K. Lilly: Numerical simulation of hydrostatic mountain waves. J. Atmos. Sci. 35, 78-107, 1978.

Peter, T., R. Müller, K. Drdla, K. Petzoldt, E. Reimer: A micro-physical box model for EASOE - preliminary results. Ber. d. dtsch. Bunsengesellschaft f. Phys. Chemie, 1992 , in press.

Schlager, H., F. Amold, D. Hofmann and T. Deshler: Balloon observations of nitric acid aerosol formation in the Artic stratosphere: I. Gaseous nitric acid. Geophys. Res. Lett., 17, 1275-1278, 1990.

Schumann, U., T. Hauf, H. Höller, H. Schmidt and H. Volkert: A mesoscale model for the simulation of turbulence, clouds and flow over mountains: formulation and validation examples. Beirr. Phys. Atmosph. 60, 413-446, 1987.

Shutts, G.J.: Observations and numerical model simulation of a partially-trapped lee wave over the Welsh mountains. Mon. Wea. Rev. 120, 1992, in press.

Xue, $M$. and A.J. Thorpe: A mesoscale numerical model using the nonhydrostatic pressure-based sigma-coordinare equations: model experiments with dry mountain flows. Mon. Wea. Rev. 119, 1168-1185, 1991.

Hans Volker and Didier Intes, DLR, Institut für Physik der Atmosphäre, D-(W) 8031 Oberpfaffenhofen, Federal Republic of Germany

(Received March 23, 1992;

revised May 13, 1992;

accepted May 19, 1992) 